\title{
Russian Scientific Workers in Foreign Laboratories.
}

$\mathrm{N}_{\text {have }}^{\mathrm{E}}$

EVER before in the history of science has there been a case when hundreds of scientific workers been exiled wholesale from their country, or have left it because they have found it impossible to continue scientific work there. This is what happened in Russia after the Bolshevist revolution took place about ten years ago ; scientific workers, with others, either had to submit to the new régime, with its somewhat unusual views on the subject of the freedom of scientific thought, or to try to seek their fortunes elsewhere. There are no statistics to tell us of the many who left their life's work and their homes behind them, only to fail in their hazardous attempts and to go down in the struggle for existence; but it is of great interest to learn that a large number of them succeeded in finding suitable occupation in various countries and have been able to continue their studies. A good idea of their work can be obtained from the bibliography of books and papers published by Russian scientific workers abroad during the period 1920-1930, issued recently by the Russian Scientific Institute founded in Belgrade with the active support of the Jugoslavian government.*

The volume contains no less than 7032 titles of books and papers published in 18 different languages by 472 Russian authors scattered all over the world, from Sofia to Stockholm, from Kharbin and IndoChina to London and Paris, and from Chicago to Rio de Janeiro. It is natural that the bulk of the titles are those of works on economics, sociology, history, philology, law, and other branches of the humanities, as well as engineering and other applied sciences, but there is an unexpectedly high percentage of works on the natural and exact sciences. Their number is 1929 and they belong to 122 authors. The list is headed by 596 works written by 38 authors on various problems of medicine and physiology, and an important place amongst them belongs to several former pupils of the famous I. Pavlov, whose methods for the study of the physiology of the nervous system are now being developed by them in a number of laboratories in Europe and in the United States. Nine Russian botanists published 121 works, amongst which the books of V. V. Lepeshkin on the chemical physiology of plants are well known to specialists. Exiled geologists number 11, and there are such celebrities amongst them as the late N. I. Andrusov (Prague) and $\mathrm{A}$. Stebutt (Belgrade), the aggregate number of publications on geology reaching 102.

* Materialy dlya bibliogra phii russkich utchenych trudov za rubezhom (1920-1930). Part 1, pp. 394. Belgrade, 1931.
Ten Russian zoologists and entomologists produced 250 books and papers, including a series of outstanding articles on comparative anatomy by M. M. Novikov (Prague), culminating in the book "Das Prinzip der Analogie und die vergleichende Anatomie " (Jena, 1930). Amongst entomological works, the world catalogue of Aphaniptera by J. N. Wagner (Belgrade) should be mentioned. Microbiologists are only three in number, but the name of $\mathrm{S}$. Metalnikoff (Paris) will be familiar to most specialists in this branch, and the 115 papers produced by them represent a valuable contribution to a number of fundamental problems. Russian chemistry, too, can be justifiably proud of the work of J. I. Bickermann (Berlin) and E. Rabinovitch (Göttingen), to mention only two of the 13 chemists with their 133 publications; while 6 physicists published 101 papers, and 200 papers and books on mathematics and mechanics have been produced by 1 I Russian workers. There are only two Russian astronomers abroad, but their names are O. Struve (Chicago) and V. Stratonov (Prague), and they published 100 papers between them. To com. plete the list, 131 papers and books on geographical subjects written by 11 authors, and 80 publications by 9 authors on agriculture, appeared during the period under review.

Striking though these figures are, they are very incomplete, because the bibliography included only the works of those Russian scientific workers who submitted lists of their papers ; many of them failed to do so for various reasons. The editors, however, hope to publish supplements to the bibliography from time to time.

It will be seen that many Russian scientific workers made full use of the opportunities offered them at various universities and laboratories, most of which have gladly opened their doors to their Russian colleagues.

Apart from contributing to the progress of science by their own original work, Russian scientific workers are also doing a great service to men of science of other nations by making available to them the results of Russian researches, which remained largely unknown abroad, by reviewing current and past Russian literature in the respective fields. It would probably not be an exaggeration to say that practically every bibliographical, or abstracting, periodical has now Russian experts on its staff, and this helps to make Russian scientific work available everywhere.

B. P. U.

\section{The Constitution of Soluble Proteins.}

THE Comptes-rendus des travaux du Laboratoire Carlsberg, vol. 18, No. 5, 1930 (Copenhagen : H. Hagerup, 1930. 6.25 Kr.), contains a long paper (in English) by Prof. Sørensen on recent work on the soluble proteins considered in the light of his theory of reversibly dissociable component systems. According to this, soluble proteins consist of a series of complexes or components, reversibly combined, $\mathrm{A}_{x}, \mathbf{B}_{y}, \mathrm{C}_{z}$. . ., these components being, for example, mainly polypeptides, but in other cases containing phosphorus, in each of which the atoms are linked by principal valencies, whereas the complexes themselves are held together comparatively loosely and reversibly by residual valencies. The strength and nature of these residual valencies depend on the chemical composition of the component in question as well as on its physical properties-above all on its dimensions and the resulting shape and surface.
Alterations in the composition of the solution (salt content, $p \mathrm{H}$, alcohol content, temperature) may give rise to reversible dissociation of the component systems and interchange of components between them. When these alterations in composition are so suited as to render possible the formation in sufficient quantities of a component system insoluble or sparingly soluble under the new conditions, such a systiem will be formed and precipitated.

It is not always easy to determine whether a given protein solution is a mixture or a true component system. Prof. Sørensen shows that the results of his investigations and his theory of reversibly dissociable components are reconcilable with Svedberg's results on the molecular weights of proteins as found by the ultra-centrifuge method. These show that only a few proteins have molecular weights exceeding a million, namely, the haemocyanins of the blood of 
some snails. The molecular weights of other proteins are, with one exception (casein, which contains protein molecules of various sizes), small multiples of about 35,000. Egg albumin and Bence Jones's albumin belong to the first group, with spheroidal molecules of radius $22 \mathrm{~A}$. and molecular weight 35,000 . Hæmoglobin and serum albumin have non-spheroidal molecules of weight 70,000 ; serum globulin belongs to the third group, with non-spheroidal molecules of weight 105,000 ; and the fourth group, with spheroidal molecules of radius $40 \mathrm{~A}$. and weight 210,000 , includes the vegetable proteins edestin, excelsin, and amandin. The results for egg albumin, by very different methods, are unanimous, and everything seems to show that it is a simple chemical unit. Serum albumin, on the other hand, has been fractionated. Although the results of Svedberg and Sjögren gave a molecular weight of about 67,500 , instead of the value 45,000 found by Sørensen, the latter does not think his product contained true decomposition products, since the fractions retained their marked power of crystallisation. He considers that reversible dissociation only had occurred. He makes a far sharper distinction, in this and other examples, between reversible dissociation and true decomposition of a protein than does Svedberg.

The nature of peptic scission is considered at length, the conclusion being reached that the breaking of peptic linkages is the sole chemical process involved, the simultaneous marked change in physical properties being due to secondary processes (hydration and disaggregation).

The name 'component systems' is now preferred to that of 'co-precipitation systems' introduced by Linderstrøm Lang, the name 'component' being used for an individual reversibly linked constituent. The real character of the molecular weights found by Svedberg is accepted, and the 'average molecular weight' found for a mixture can give valuable information.

In the experimental part, emphasis is laid on the importance of determining the distribution of the components of the dispersion medium between the solution and the undissolved phase, and a number of examples from previous memoirs, as well as new investigations, are summarised in this section. Some tendency to reversible dissociation was detected with egg albumin. Serum albumin was separated into three groups of fractions differing in solubility, irrespective of whether the fraction in question is phosphorus-containing or not. The various fractions differed very little in chemical composition, and two almost identically composed substances may be widely different in solubility, a result which is not due to denaturation. Casein has a very considerable tendency to dissociation, but is not regarded as a mixture. Its ionisability in presence of acid or alkali gives rise to component systems with a much greater dissociating tendency than that of uncharged or isoelectrically charged systems.

The question of protein systems in serum is considered. They are regarded as in continual mutual interaction, forming new systems, the composition of which depends on concentration and other conditions, and the proteins may not correspond with those precipitated by salts. The question which this suggests, whether it is reasonable to retain the old terms serum albumin and serum globulin, is considered, the answer being in the affirmative.

The interesting relation between lipoids and proteins in serum is discussed, particular attention being given to Mâchebœuf's experiments. The latter obtained from horse-serum a product which he regarded as a chemical compound of lecithin, cholesterol ether, and protein, from which lipoids cannot be extracted by ether, and in which the protein is not, or is only slowly, denatured by alcohol at the ordinary temperature. This conclusion is accepted, and it is suggested that the perfect clearness of such liquids as serum and plasma, in spite of their high lipoid content, is explicable only by assuming linkages between the lecithin and sterols on one side and the proteins on the other. The linkage between lipoid and protein is weak and may be split in emulsification processes; a real chemical linkage is not probable.

It will be seen from the above brief summary that Prof. Sørensen's authoritative memoir raises many questions of considerable interest and importance, both from the chemical and the biological points of view, and it may be welcomed as a brief yet comprehensive summary of recent work in that branch of protein investigation to which its author has made so many important contributions.

\section{General Biology in the "Encyclopædia Britannica".}

$\mathrm{A}^{\mathrm{NY}}$ criticism of the articles on general biology in A the "Encyclopædia Britannica" must take into consideration, first, the fullness and accuracy of the information contained in them, and secondly, the mode of presentation. For it is surely not sufficient to provide a summary, however authoritative, of any branch of science, if this is presented in such a manner that it cannot be understood by the general reader. It is for his benefit that the "Encyclopædia" is, presumably, issued, and its financial success is certainly dependent upon his willingness to purchase it.

There are some branches of physical science in particular which cannot be presented to the public in an intelligible manner. Both the subject matter and language employed are alien. But this has not in the past been true of biology. Here the general reader has felt confident of understanding articles written about it. It is in some degree a measure of the very definite advance which biology has made in the past generation that the general reader will not infrequently find these biological articles difficult of comprehension. But the fault does not always lie solely in the subject matter, for several of the authors have shirked the admittedly difficult task of presenting their information in plain English and taken the easier way of scientific 'shorthand'. The more intricate biology becomes, the greater the need for clear writing in articles such as these.

It is pleasant to find, therefore, that the articles which will probably be most frequently consulted by the general reader, evolution by Prof. E. S. Goodrich and zoology by Prof. D. M. S. Watson, are wholly admirable in both their scope and presentation. No biologist can read them without having his ideas clarified, and no layman can fail to understand them or to be impressed by the range of knowledge they display. The only criticism we have concerns the article on evolution. Here the vital need, in Darwin's opinion, of natural selection as the mechanism which prevented the swamping, as he thought, of any favourable variation by promiscuous interbreeding, is not stated. The reader is left with the impression that Darwin realised, as his successors do to-day, that there was such a thing as segregation which makes swamping impossible.

Prof. J. B. S. Haldane has made the best of a very difficult task in his article on heredity. It is not easy reading, but, in view of the nature of the facts with which it deals, this could not be avoided, and the

No. 3201, VoL. 127] 